\title{
Impact of Korean Ginseng (Panax Ginseng) on Power Generation of Microbial Fuel Cells
}

\author{
Wonjae Kim ${ }^{1}$, Peter $\mathrm{Lee}^{2}$, Thomas W. $\mathrm{Kim}^{3}$, George Kim ${ }^{1}$, Jonathan Sukhee Chung ${ }^{4}$, Jihwan Alex. Joo ${ }^{5}$ and \\ Sung-Jae Chung $1,6,7^{*}$ \\ 1. Fuzbien Technology Institute, MD 20850, United States \\ 2. Collegiate School, NY 10024, United States \\ 3. Department of Chemistry, University of Illinois-Urbana Champaign, IL 61801, United States \\ 4. Centreville High School, VA 20124, United States \\ 5. Seoul International School, Seoul 13113, South Korea \\ 6. School of Arts and Sciences, Marymount University, Arlington 22207, United States \\ 7. STEM Research Institute, VA 22031, United States
}

\begin{abstract}
This study reports an increase in power generation of a MFC (microbial fuel cell) by the addition of Korean ginseng (Panax ginseng). It was noted that the use of ginseng enhances the microbial anaerobic degradation of cellobiose, a disaccharide that was used as a substrate in the anode chamber of the MFC. The power output of the MFC where ginseng was added showed noticeable enhancement compared to the control MFC. The increase slowly ramped at the initial days and became appreciably higher after the 11th day of incubation in an experiment set up for 16 days duration. It is attributed that the ginseng increases the $\mathrm{CO}_{2}$ production by accelerating the fermentation process. Decrease in $\mathrm{CH}_{4} / \mathrm{CO}_{2}$ ratio was observed also due to decrease in methane production per digested cellobiose, the proton donor in the current study. Four ring steroid-like structural moiety Ginsenoside of Panax ginseng seemed to play a beneficial role in the electron transfer from cellobiose to the anode, perhaps by rendering easier electron transfer due to favorable energy level alignments.
\end{abstract}

Key words: MFC, Korean ginseng, Panax, anaerobic degradation.

\section{Introduction}

Renewable energy research has received a lot of impetus as recourse to the society's excessive dependence on rapidly depleting fossil fuel. Renewable bioenergy is one of the best alternate energy sources owing to a large supply of the necessary biomass and the feasibility of establishing a viable electrochemical technology for power production from them, which has been already demonstrated in principle and prototypes. Therefore, this area of research legitimately deserves a lot of attention in order to develop and refine the design and process technologies that can meet electricity demands in economically and commercially viable ways.

\footnotetext{
*Corresponding author: Sung-Jae Chung, professor, research field: organic chemistry.
}

MFC (microbial fuel cell) is a bio-electrochemical system that converts chemical energy contained in organic matter into electrical energy in an electrochemical cell. The active electron transfer to the electrodes is accomplished by the catalytic (metabolic) activity of living microorganisms (microbes) [1]. This is an attractive technology for it attempts to meet energy endeavors as well as environmental concerns. The use of biomass as fuel helps lower the carbon foot print and the extraction of electricity directly through an electrochemical cell removes the Carnot efficiency limitation. It has been demonstrated that any compound that can be disintegrated, such as the ones that may be metabolized by bacteria, can be used to produce electricity [2]. The MFC, as an electrochemical cell, 
consists of an anode and a cathode compartments that are separated by a PEM (proton exchange membrane) or cation-specific membrane. The anode compartment is made of an anaerobic chamber (because presence of oxygen inhibits anodic process) where a substrate is placed on which colony of microbes can grow. The substrates consist of a range of chemical compounds ranging from simple, pure, low molecular sugars to complex organic matter e.g. carbohydrates, proteins, volatile acids, cellulose and wastewater. In most of the MFCs, acetate is a preferred substrate because it is inert towards microbial conversions (fermentations and methanogenesis) and can generate high coulombic efficiency and power output [3]. Glucose and Xylose are also regarded as good choices as they have shown high coulombic efficiencies.

\section{Experimental Sections}

\subsection{Process of Methanogenesis via Electron Transference}

The anodic process comprises of the microbes oxidizing the substrate to generate electrons and protons. The electrons are accepted by the anode and transferred through an external circuit to the cathode via a load (resistor) across which a potential drop takes place. The protons diffuse through the electrolytic solution to the cathode across the PEM. where electrons combine with protons and oxygen to form water [4]. Methanogenesis $\left(\mathrm{CO}_{2}+4 \mathrm{H}_{2} \rightarrow \mathrm{CH}_{4}\right.$ $+2 \mathrm{H}_{2} \mathrm{O}$ ) in microorganisms in anode chamber can be thought to decrease the electricity production by anaerobic respiration where carbon serves as a terminal electron acceptor. Anodic methane producing methanogens was reported not to affect the electricity production but in fact co-existed with electricity-producing bacteria, mostly on the surface as well as inside the anode [4], however decrease in proton diffusion to cathode chamber should combine the decrease in electron transfer and an unknown factor might compromise the loss of proton for methanogenesis in the whole system.

\subsection{Structure of Ginsenoside and Degradation of Cellobiose}

Ginseng saponins, or ginsenosides, have a four ring, steroid-like structure with sugar moieties attached. They are the main bioactive molecules responsible for the actions of ginseng and show properties similar to acetylcholine, adrenaline, histamine, and opioids [5]. Results have indicated that saponins have a strong anti-protozoal activity and could thus serve as an effective defaunating agent for ruminants due to their detergent action [6]. Mitigation of methanogenesis using tea saponins results from decreased activity of the morA gene, which is an indicator of the methanogenic activity of the methanogen population in rumen culture for in vitro studies [7]. Methanol extract $(4 \mathrm{mg} / \mathrm{mL})$ of Sapindus rarak containing saponins reduced the concentration of methanogen RNA (ribonucleic acid) [7]. Low saponin concentrations indirectly influence methane production in the rumen by reducing the number of protozoa, whereas higher saponin concentrations have direct negative effect on methanogens [8]. With this back ground, in the present work, a study was performed to evaluate the effects of adding ginseng into anode chamber on methanogenesis and electricity production. The primary purpose of our study was to determine the effects of Korean Ginseng (Panax ginseng) on anaerobic degradation of cellobiose in the MFC. The authors used an H-shape MFC cell design to maintain anaerobic conditions in the anode chamber. I-V measurements were carried out on the electrochemical cell set ups. From the measurements of the power outputs of the MFC, it was clear that the use of Ginseng resulted in a perceptible increase in the volume of methane as well as in power output when compared to the control (MFC without ginseng). Thus, the cellobiose degradation is significantly enhanced by the Ginseng powder.

\subsection{The Addition of Cellobiose}

An H-type MFC was used for this study (Fig. 1). 
Two $125 \mathrm{~mL}$ glass jars acting as the anode and cathode chambers each with butyl rubber stoppers were connected through a flange on the sides where a cation exchange membrane (CMI-7000S, Membranes International Inc.) was placed for the proton transport (Fig. 1).

The microbes employed in this experiment were a particular type of bacteria retrieved from dairy manure. The anode chamber was filled with $100 \mathrm{~mL}$ of dairy manure collected from anaerobic digester in a dairy farm. To the anode chamber, $2 \%(\mathrm{w} / \mathrm{v})$ of cellobiose (C7252, Sigma-Aldrich) was added that served as the substrate and hence the electron donor. The cathode chamber was filled with $100 \mathrm{~mL}$ of phosphate buffered saline. It may be recalled that PBS (phosphate buffered saline) is a $\mathrm{H}_{2} \mathrm{O}$ based salt solution and acts as a buffer solution in most biological studies and it primarily consists of $\mathrm{NaCl}$, $\mathrm{KCl}, \mathrm{Na}_{2} \mathrm{HPO}_{4}$, and $\mathrm{KH}_{2} \mathrm{PO}_{4}$.

\subsection{Analyzing and Isolating control Group Assemblies}

The authors divided our experiments into two sets - a trial with a control group where no Ginseng was added and the other part with the addition of Ginseng powder. For the latter experiments, $100 \mathrm{mg}$ of dried ginseng powder was added into the anode chamber.

The anode and cathode were connected externally by $430 \Omega(0.25 \mathrm{~W})$ resistor and internally through the PEM. An empty Mylar balloon was attached through the butyl rubber stopper onto the anode chamber of both sets to collect the formation gases. After the assemblies were complete (essentially identical except for the addition of Ginseng), the MFCs were incubated at room temperature $\left(25^{\circ} \mathrm{C}\right)$ for up to 15 days i.e. from d0 (Initial day) to d15 (day 15). As the incubation time and the microbe activity progressed, methanogenesis occurred and the gasses were collected in the Mylar balloons. The gas volumes were measured using glass syringes. Two prominent types of gases $-\mathrm{CO}_{2}$ and $\mathrm{CH}_{4}$ were collected. They were identified by analyzing them with an Agilent 6890 series gas chromatograph equipped with a thermal conductivity detector and a stainless steel packed column containing 60/80 Carboxen 1000 (Superlcol-2390 U).

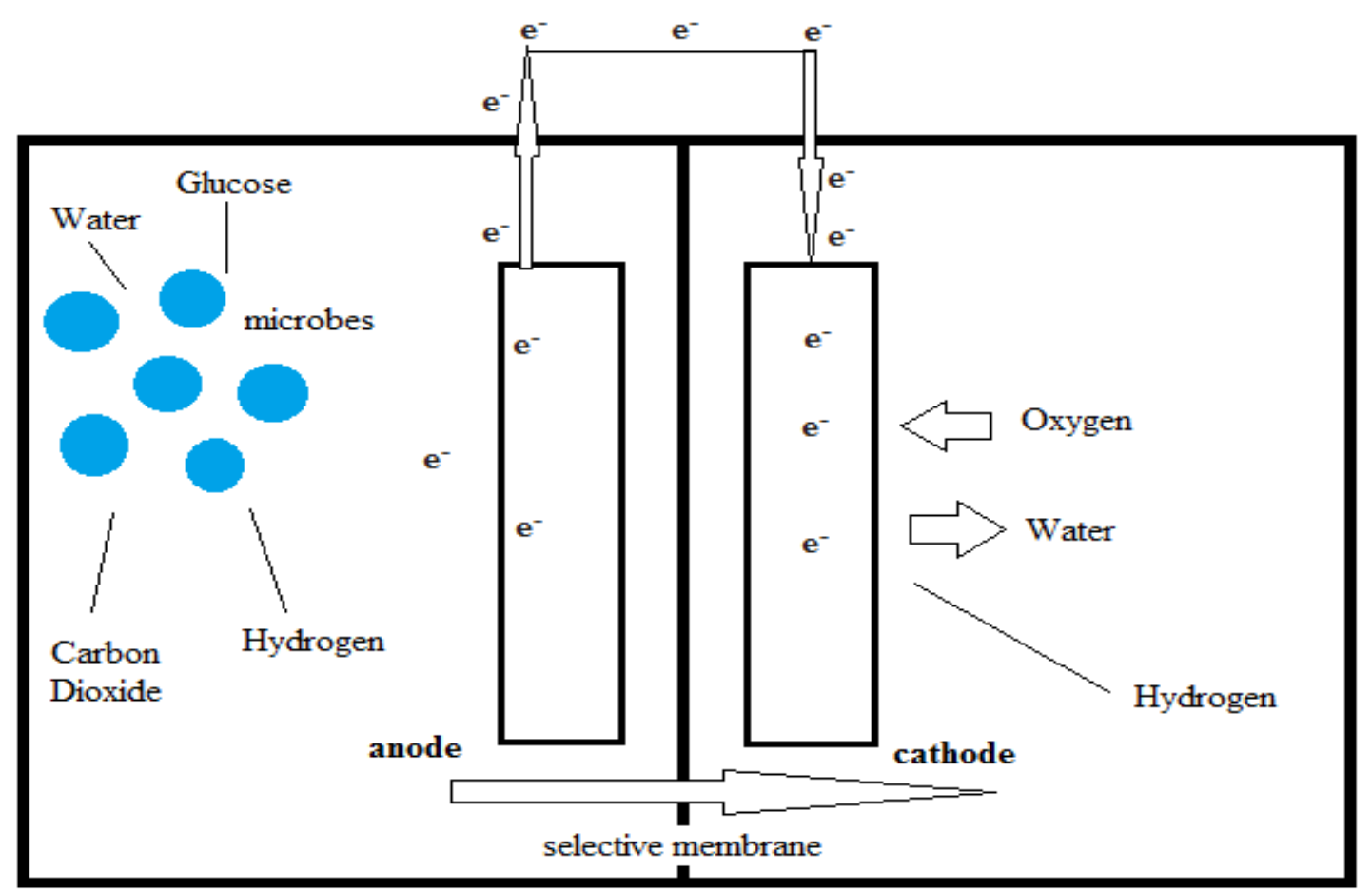

Fig. 1 The working principle of a MFC. 
The MFC voltage across the $430 \Omega$ external resistor was measured using a multimeter with a data acquisition (Model 2700, Keithley Instruments Inc., Cleveland, OH, USA). The power density was calculated according to $P=I \times V / A$, with $\mathrm{I}=$ current, $V=$ voltage, $R=$ external resistance, and $\mathrm{A}\left(\mathrm{m}^{2}\right)=$ the projected area of the cathode. Statistical analysis was performed by a t-test with significance declared at $\mathrm{P}<0.05$.

\section{Results and Discussion}

Korean Ginseng, has been renowned for its valuable and intrinsic influence in eastern medicine from countries such as China, Korea, and Japan for nearly 2,000 years. As a plant most commonly used for herbal medicine, Panax ginseng is chemically characterized to have a 4 ring steroid-like structure that share similar properties with acetylcholine, adrenaline, histamines, and opioids.

Shown in Table 1 are the data of gas production where it should be noted that the methane production changed little between the control and ginseng treatments $(310.8 \mathrm{~mL}$ and $350.4 \mathrm{~mL}$, respectively) whereas the carbon dioxide production increased $106.6 \mathrm{~mL}$ to $183.9 \mathrm{~mL} ; P=0.0337$, thus decreasing the $\mathrm{CH}_{4}$ to $\mathrm{CO}_{2}$ ratio from 2.92 to 1.9. The total gas measured in the control group was $417.2 \mathrm{~mL}$ whereas the Ginseng group measured a total gas $534.2 \mathrm{~mL}$. Both methane and carbon dioxide being fermentation products, the increase in gas production reflects the improved fermentation.

As shown in Table 2, the current densities showed an appreciable difference between the Ginseng and control groups. This is a good evidence of the assisted and enhanced electron transfer rate achieved in the Ginseng group. Another key observation during the experiment was that the readings of cell potentials of the MFCs the control and the Ginseng group (Table 3 and Fig. 3). From d11, the cell potential $\left(V_{o c}\right)$ of MFC with Ginseng in the anode measured 2.066 and started to gradually decrease. On $\mathrm{d} 12$, the Ginseng in the anode measured 1.682 and decreased to 1.461 , 1.548 , and 1.082 (d13, d14, and $\mathrm{d} 15$ respectively). The $V_{\text {oc }}$ of the control group also decreased gradually from 1.294 on d 11 to 0.431 on $\mathrm{d} 12$ and continued as $0.482,0.396$, and 0.309 (d13, d14, and $\mathrm{d} 15$ respectively).

On the other hand, the current measurement (Table 2) did not show such a trend. Depletion of substrate or accumulation of fermentation product might cause the overall decrease in power yield because the batch system was used in current study. No substrate or fermentation media was added until the end of experiment. Furthermore, it should be noted that in the initial 10 days, the gas quantities and the $V_{\text {oc }}$ 's were essentially identical for both the MFC's. Presumably, the microorganisms that existed in dairy manure caused the lag for buildup on anode when no mediator was present.

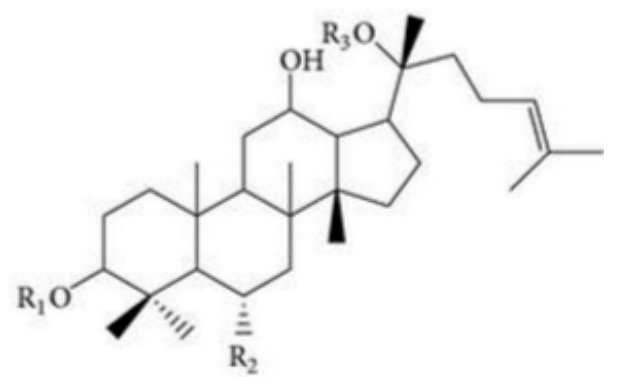

Fig. 2 The chemical structure of Ginsenoside, the main constituent of Korean Ginseng.

Table 1 Gas composition and production in the anode chamber during 15d incubation with or without addition of ginseng powder.

\begin{tabular}{lcccl}
\hline Incubation time & $\mathrm{CH}_{4}(\mathrm{Ml})$ & $\mathrm{CO}_{2}(\mathrm{~mL})$ & Total gas $(\mathrm{mL})$ & $\mathrm{CH}_{4} / \mathrm{CO}_{2}$ \\
\hline Control & 310.8 & $106.6^{\mathrm{b}}$ & 417.4 & $2.92^{\mathrm{b}}$ \\
Ginseng & 350.4 & $183.9^{\mathrm{a}}$ & 534.5 & $1.91^{\mathrm{a}}$ \\
$\mathrm{SEM}^{\mathrm{c}}$ & 20.99 & 10.30 & 30.15 & 0.127 \\
$\mathrm{P}^{\mathrm{d}}$ & 0.3129 & 0.0337 & 0.1111 & 0.0301 \\
\hline
\end{tabular}

${ }^{\mathrm{ab}}$ Means within a column with different superscripts differ $(\mathrm{P}<0.05) ;{ }^{\mathrm{c}}$ standard error of means; ${ }^{\mathrm{d}}$ mean standard deviation. 
Table 2 Current density $\left(\mathrm{A} / \mathrm{m}^{2}\right)$ during the single batch of cellobiose fermentation by digester inoculate with or without addition of ginseng powder.

\begin{tabular}{lllll}
\hline Incubation time & Ginseng & Control & Standard deviation & $P$ \\
\hline $\mathrm{d} 11$ & 2.066 & 1.294 & 0.164 & 0.0795 \\
$\mathrm{~d} 12$ & $1.682^{\mathrm{a}}$ & $0.431^{\mathrm{b}}$ & 0.098 & 0.0120 \\
$\mathrm{~d} 13$ & $1.461^{\mathrm{a}}$ & $0.482^{\mathrm{b}}$ & 0.149 & 0.0436 \\
$\mathrm{~d} 14$ & $1.548^{\mathrm{a}}$ & $0.396^{\mathrm{b}}$ & 0.096 & 0.0137 \\
$\mathrm{~d} 15$ & $1.082^{\mathrm{a}}$ & $0.309^{\mathrm{b}}$ & 0.123 & 0.0472 \\
\hline
\end{tabular}

${ }^{\mathrm{ab}}$ Means within a row with different superscripts differ $(P<0.05)$.

Table $3 \mathrm{~V}$ (Voltage ) and incubation time (days) during the single batch of cellobiose fermentation by digester inocula with or without addition of ginseng powder.

\begin{tabular}{lllll}
\hline Day & Ginseng & Control & Ginseng & Control \\
\hline 11 & 0.327 & 0.258 & 0.058 & 0.034 \\
12 & 0.345 & 0.148 & 0.070 & 0.023 \\
13 & 0.275 & 0.154 & 0.067 & 0.020 \\
14 & 0.283 & 0.142 & 0.077 & 0.022 \\
15 & 0.236 & 0.126 & 0.043 & 0.027 \\
\hline
\end{tabular}

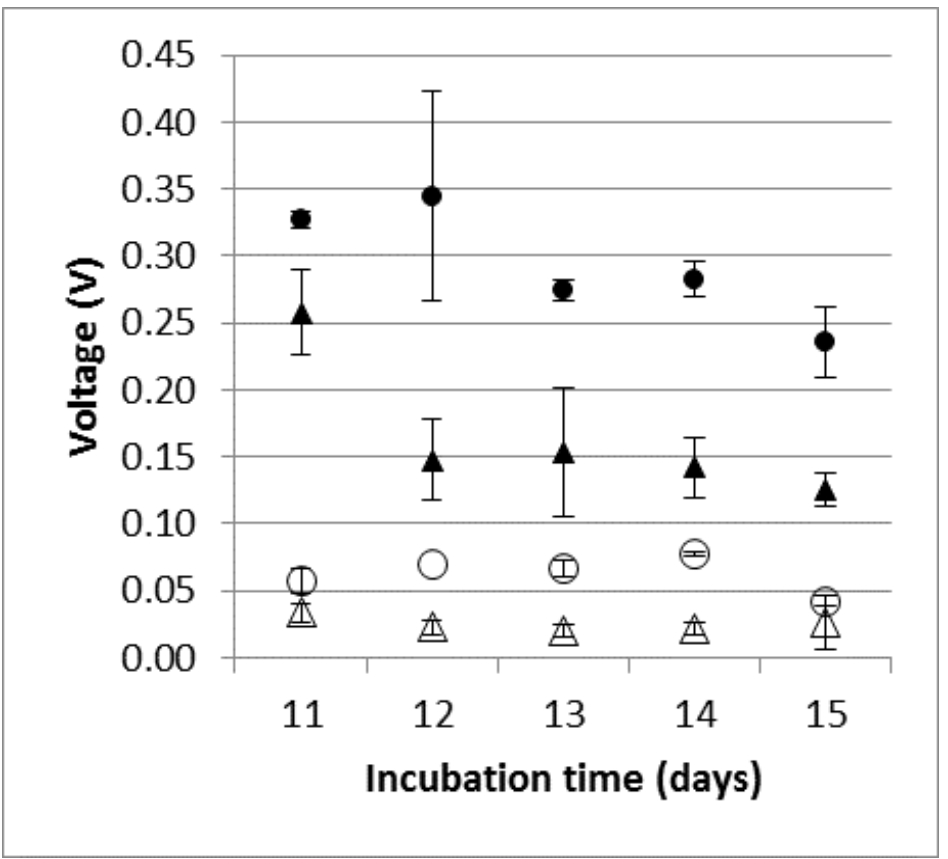

Fig. 3 Power yield by dairy manure incubation on cellobiose over 15 days. Voltage $(V)$ measured directly from cathode and anode (filled $\bullet$ ) or across resistor $(430 \Omega$ ) connected between cathode and anode (empty :).

Ginseng addition improved $(P<0.05) V_{\mathrm{oc}}$ and current density with the addition of ginseng. The greater power yield generally can be attributed to more efficient electron transfer from anode and perhaps more proton diffusion to the cathode. In the current study we observed decreased production of $\mathrm{CH}_{4}$ (proton scavenger) per substrate fermented in anode chamber. Ginseng might affect only total substrate fermentation with lower methane production or both fermentation improvement and electron transfer on anode.

\section{Conclusions}

This work demonstrates the beneficial effect of Korean Panax Ginseng in the electrochemistry of a MFC. The authors have hypothesized that the ginseng 
provides an electron pathway from the bacteria to the anode by helping decrease the potential barriers between the electron donor and the anode. Though the authors have not carried out a quantitative study on whether the ginseng's effect can be scaled up by loading variable amounts the anode chamber, it still illustrates that the electron transfer process can be assisted and enhanced by this ubiquitous medicinal material.

\section{Acknowledgements}

This study was financially supported by STEM research Institute (Grant No. MFC-2013).

\section{References}

[1] Allen, R. M., and Bennetto, H. P. 1993. "Microbial Fuel-cells." Appl. Biochem. Biotechnol. 39 (1): 27-40

[2] Pant, D., Bogaert, G. V., Diels, L., and Vanbroekhoven, K. 2010. "A Review of the Substrates used in MFCs (Microbial Fuel Cells) for Sustainable Energy Production." Biores Technol. 101 (6): 1533-43.

[3] Mathuriya, A. S., and Sharma, V. N. 2009. "Bioelectricity Production from Various Wastewaters through Microbial Fuel Cell Technology.” J. Biochem. Tech. 1 (2): 49-52.

[4] Kaku, T., Miyata, T., Uruno, T., Sako, I., and Kinoshita, A. 1975. "Chemico-Pharmacological Studies on Saponins of Panax Ginseng C. A. Meyer. II. Pharmacological Part." Arzneimittel-Forschung 25 (3): 539-47.

[5] Makkar, H. P. S., Sen, S., Blummel, M., and Becker, K. 1998. "Effect of Fractions Containing Saponins on Rumen Fermentation." J. Agri. Food Chem. 46 (10): 4324-8.

[6] Guo, Y. Q., Liu, J. X., Lu, Y., Zhu, W. Y., Denman, S. E., and McSweeney, C. S. 2008. "Effect of Tea Saponin on Methanogenesis, Microbial Community Structure and Expression of McrA Gene, in Cultures of Rumen Micro-organisms." Letters Applied Microbiology. 47 (5): 421-6.

[7] Wina, E., Muetzel, S., Hoffmann, E., Makkar, H. P. S., and Becker, K. 2005. "Saponins Containing Methanol Extract of Sapindus Rarak Affect Microbial Fermentation, Microbial Activity and Microbial Community Structure in Vitro." Animal Feed Science and Technology 121 (1-2): 159-74.

[8] Bodas, R., Prieto, N., Garci'a-Gonza'lez, R., Andre's, S., Gira'ldez, F. J., and Lo'pez, S. 2012. "Manipulation of Rumen Fermentation and Methane Production with Plant Secondary Metabolites." Animal Feed Science and Technology 176: 78-93. 